Original Article

\title{
A cross sectional study on community prevalence and treatment practice of hypertension with household awareness about it in semi urban Mangalore - A pilot study
}

\author{
Navya N. ${ }^{1}$, Rashmi Kundapur ${ }^{2} \&$ N. Udaya Kiran ${ }^{3}$ \\ ${ }^{1}$ Postgraduate, ${ }^{2}$ Professor, ${ }^{3}$ Professor $\&$ HOD, Department of Community Medicine \\ K.S. Hegde M edical Academy, Nitte University, M angalore \\ Correspondence \\ Navya $\mathbf{N}$. \\ Post Graduate, Department of Community M edicine, K.S. Hegde M edical Academy, \\ Nitte University, M angalore - 575 018, Karnataka, India. \\ E-mail : navya1211@yahoo.com
}

\begin{abstract}
Objectives: 1. To determine the community prevalence of hypertension.

2. To Assess the Household Awareness Of hypertension.

3. To study the pattern and regularity of treatment in hypertensives.
\end{abstract}

Introduction: Hypertension, also known as high or raised blood pressure, is a global public health issue and is the major contributory factor for the burden of heart disease, stroke, renal failure, premature mortality and morbidity worldwide.

Methodology: A cross sectional study was carried out in 40 Households of Grama-Kshema Project in Kuthar and Manjanady villages (semi urban ) which belong to the field practice area of K.S. Hegde M edical Academy, M angalore. A structured Questionnaire was used to collect data. Questions on awareness were scored and analyzed.

Results: The community prevalence of hypertension among the households surveyed was 9.6 percent out of which $12.5 \%$ were female and $5.9 \%$ were male. Among them $46.7 \%$ were in the age group $51-70$ years, $40 \%$ in the age group $31-50$ years and $13.3 \%$ in the age group above 70 years. $40 \%$ of hypertensive visit their doctor on monthly basis. $66.7 \%$ of the hypertensives visit private dispensary for their treatment and follow up. 93.3\% are on anti-hypertensives of which $33.3 \%$ use calcium channel blockers. Awareness scoring showed that $40 \%$ had poor score and $37.5 \%$ average score.

Conclusions: In the present study the prevalence of hypertension was found to be low. Among those diagnosed of hypertension, majority of them were females. Most of the hypertensive's visit private dispensaries on monthly basis. Awareness of Hypertension among the households was poor.

Key words: Hypertension, Awareness, Prevalence

\section{Introduction}

Hypertension, also known as high or raised blood pressure, is a global public health issue. It is one of the major contributory factor to the burden of heart disease, stroke, renal failure and premature mortality and disability. The health systems being weak Access this article online Quick Response Code

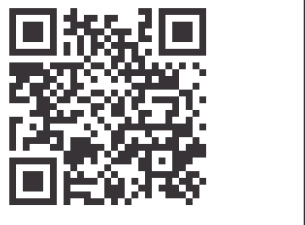

in low and middle income countries results in affecting the population disproportionately. In 2008 , worldwide, approximately $40 \%$ of adults aged 25 and above had been diagnosed with hypertension. ${ }^{1}$ Prevalence of hypertension has increased in both urban and rural subjects and presently is 25\% in urban adults and $10-15 \%$ among rural adults. ${ }^{2}$ The size of the elderly segment of the population is increasing in developing countries as the latter undergo a demographic transition, with a concomitant increase in life expectancy. It is estimated that majority of the elderly people worldwide will reside in developing countries by the year 2025.Developing countries are thus likely to face an enormous burden of chronic non-communicable Diseases like hypertension in the near future. ${ }^{3}$ Early detection of hypertension minimizes the risk of heart attack, cardiac failure, stroke and renal 
failure. As with other non-communicable diseases, selfcare can facilitate early detection of hypertension, adherence to medication and healthy behaviours, better control and awareness of the importance of seeking medical advice when necessary. ${ }^{1}$ Hence there is a need to assess the present burden of the disease as well as the awareness regarding the same among the general population.

Hence we have undertaken this study with the following objectives:

1. To determine the community prevalence of hypertension.

2. To Assess the Household Awareness Of hypertension.

3. To study the pattern and regularity of treatment in hypertensive's.

\section{Materials and M ethods}

This is a cross sectional study which was carried out in 40 Households of Kuthar and M anjanady villages (semi urban) in M angalore. Kuthar and $M$ anjanady villages belong to the field practice area of K.S. Hegde Medical Academy, Mangalore. The households selected for this pilot study belong to the GramaKshema project.

The project involves allotment of 40 needy families in Kuthar and Manjanady villages to $1^{\text {st }}$ year M BBS students, where a group of 3 students are allotted one family each and the progress of the project is monitored by a staff and 2 postgraduate students. They make regular visits to the family and obtain information on their health status and provide continuous care till they complete their MBBS course. These families are covered under the KSHEMA health card and necessary support is given by K.S. Hegde Charitable hospital.

A structured questionnaire was used to gather information regarding prevalence of diagnosed hypertensives in the households, their treatment seeking behavior, treatment patterns and lifestyle modifications. The questionnaire also had 12 questions to assess the awareness regarding hypertension among the households.

The questions were categorized into 2 catego ries based on priority. There were 8 high priority questions and 4 low priority ones. Each correct answer for question belonging to high priority category was awarded 1.5 marks, for every wrong answer 1.5 marks was deducted and for those who gave answer as don't know were awarded 0 mark. Low priority questions were awarded $+1,-1$ and 0 mark each. The total score was calculated which ranged between 0 to 28. Likert scale was used to categorize the awareness scoring.

Data was entered in M S excel and statistical analysis was done using SPSS version 16. Frequencies and percentages were calculated. Association between hypertension and gender was calculated using Chi square analysis. Mann whitney test was used to check association between gender and awareness scoring, Kruskal- wallis $\mathrm{H}$ test used for age groups and awareness scoring.

\section{Results}

Our study showed that out of the 156 people surveyed hypertension had been diagnosed in 15 of them, thereby giving the community prevalence rate of $9.6 \%$ (Fig 1 ). The duration of hypertension was $0-5$ years in 40\%, 6 - 10 years in 33.3\%, $11-15$ years in 20\% and more than 16 years in $6.7 \%$ of the hypertensive population (Table3).

Hypertension was observed in $5.9 \%$ of males and $12.5 \%$ of females. There was no statistical difference in the prevalence of hypertension between males and females. Among the general population $46.7 \%$ of people in age group $51-70$ years, $40 \%$ in the age group $31-50$ years and $13.3 \%$ in the age group above 70 years had hypertension (Table 2). Among those diagnosed with hypertension $26.7 \%$ are in the age group of $41-50$ years, $26.7 \%$ in age group of $61-70$ years, $20 \%$ in age group of $51-60$ years, $13.3 \%$ in the age group of $30-40$ years and more than 71 yearseach.

$93.3 \%$ of those diagnosed of hypertension are on antihypertensives and $6.7 \%$ are not on any medication. $33.3 \%$ are on calcium channel blockers, $20 \%$ on beta blockers, 13.3 $\%$ on ACE inhibitors, $6.7 \%$ on angiotensin receptor blockers, $6.7 \%$ on Calcium channel blockers +beta blockers, $6.7 \%$ on 
Calcium channel blockers + angiotensin receptor blockers,

$6.7 \%$ on others and no treatment (Table 3 ).

Complications due to hypertension were seen in $6.67 \%$ of the hypertensives. Ischemic heart disease was the common complication seen in this study (Table 3).

Frequency of visit to health care facilities showed that $40 \%$ visit on monthly basis, $26.7 \%$ on weekly basis, $13.3 \%$ once in 6 months and $20 \%$ visit irregularly (Table 3). In our study we found that $66.7 \%$ utilize health care facilities from private dispensaries, $26.6 \%$ from KSHEM A and $6.7 \%$ from nearby PHCs (Fig 3).

Majority of the hypertensives (73.3\%) do not exercise and there was no difference in physical activity before and after diagnosis. Diet modification was reported by $53.3 \%$ of hypertensives whereas $46.7 \%$ had no modifications in their diet.

Awareness scoring showed that $40 \%$ had poor knowledge, $37 \%$ had average knowledge, $17.5 \%$ had very poor knowledge and only 5\% had good knowledge regarding hypertension (Fig 4). There was no statistically significant difference in the awareness between males and females, as well as in different age groups.

Fig. 1 : Prevalence of Hypertension $(n=156)$

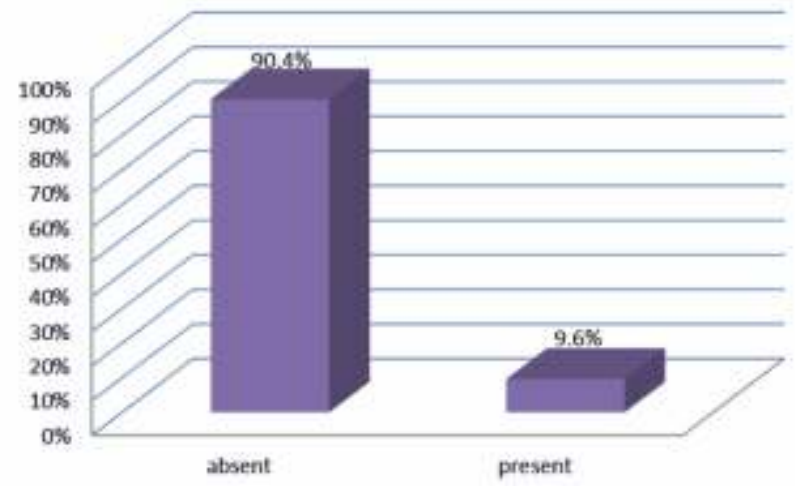

Table 1: GENDER WISE DISTRIBUTION OF HYPERTENSION( $n=156$ )

\begin{tabular}{|c|l|l|l|}
\hline \multirow{2}{*}{ Gender } & \multicolumn{2}{|c|}{ Hypertension } & \multirow{2}{*}{ Total } \\
\cline { 2 - 3 } & absent & present & \\
\hline Male & 64 & 4 & 68 \\
& $45.4 \%$ & $26.7 \%$ & $43.6 \%$ \\
\hline Female & 77 & 11 & 88 \\
& $54.6 \%$ & $73.3 \%$ & $56.4 \%$ \\
\hline Total & 141 & 15 & 156 \\
& $100.0 \%$ & $100.0 \%$ & $100.0 \%$ \\
\hline
\end{tabular}

Fig. 2 : Hypertensives With Diabetes M ellitus $(n=1256)$

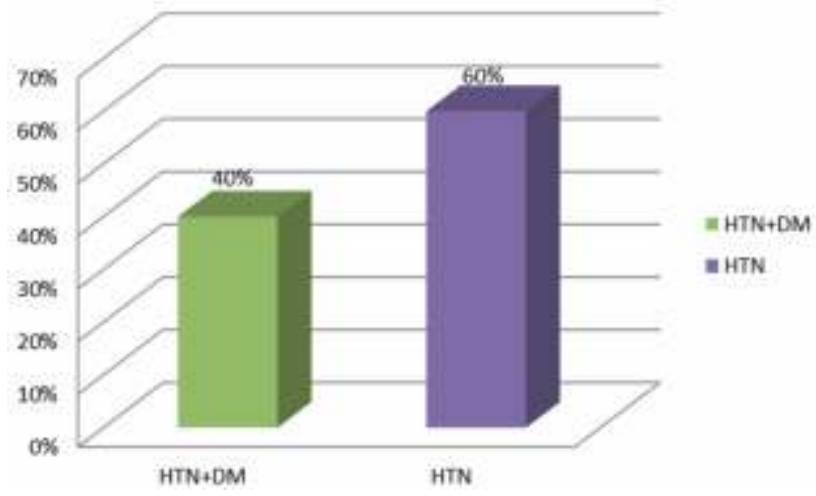

$\mathrm{HTN}=$ Hypertension

HTN +DM = Hypertension and Diabetes Mellitus

Fig. 3 : Health care Facility Utilized $(n=15)$

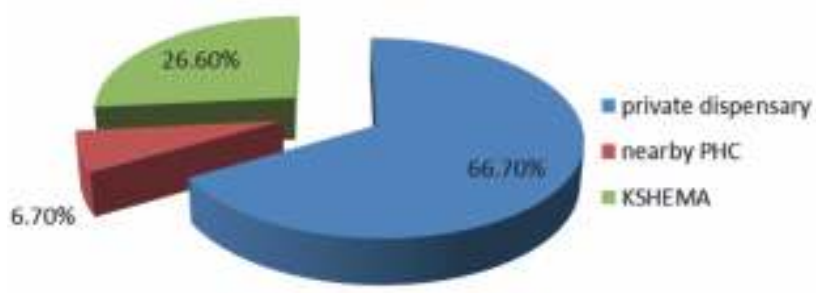

Fig. 3 : Household Awareness of Hypertension $(n=40)$

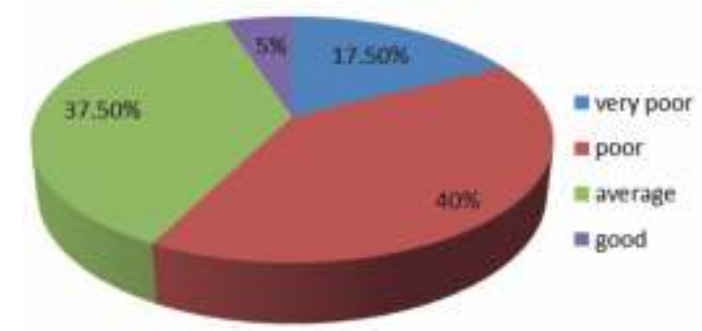

Table 2 : DISTRIBUTION OF HYPERTENSION WITH RESPECT TO $\operatorname{AGEGROUPS}(n=156)$

\begin{tabular}{|c|c|c|c|c|c|}
\hline \multirow[t]{2}{*}{ Hypertension } & \multicolumn{4}{|c|}{ Age Group } & \multirow[t]{2}{*}{ Total } \\
\hline & $18-30$ & $31-50$ & $51-70$ & $>71$ & \\
\hline \multirow[t]{2}{*}{ Absent } & 58 & 60 & 23 & 0 & 141 \\
\hline & $41.1 \%$ & $42.6 \%$ & $16.3 \%$ & $0 \%$ & $100.0 \%$ \\
\hline \multirow[t]{2}{*}{ Present } & 0 & 6 & 7 & 2 & 15 \\
\hline & $0 \%$ & $40.0 \%$ & $46.7 \%$ & $13.3 \%$ & $100.0 \%$ \\
\hline \multirow[t]{2}{*}{ Total } & 58 & 66 & 30 & 2 & 156 \\
\hline & $37.2 \%$ & $42.3 \%$ & $19.2 \%$ & $1.3 \%$ & $100.0 \%$ \\
\hline
\end{tabular}

\section{Table 3}

\begin{tabular}{|l|l|c|}
\hline Variable ( $\mathbf{n = 1 5})$ & Categories & Percentages \\
\hline Duration of hypertension & $0-5$ years & $40 \%$ \\
\hline & $6-10$ years & $33.3 \%$ \\
\hline & $11-15$ years & $20 \%$ \\
\hline & $>16$ years & $6.7 \%$ \\
\hline Usage of Antihypertensives & Use & $93.3 \%$ \\
\hline & Do not use & $6.7 \%$ \\
\hline
\end{tabular}




\begin{tabular}{|c|c|c|}
\hline Variable $(n=15)$ & Categories & Percentages \\
\hline \multirow[t]{8}{*}{$\begin{array}{l}\text { Types Of Antihypertensives } \\
\text { used }\end{array}$} & $\begin{array}{l}\text { Calcium channel } \\
\text { blockers }\end{array}$ & $33.3 \%$ \\
\hline & Beta blockers & $20 \%$ \\
\hline & ACE inhibitors & $13.3 \%$ \\
\hline & $\begin{array}{l}\text { Angiotensin receptor } \\
\text { blockers (ARB) }\end{array}$ & $6.7 \%$ \\
\hline & $\begin{array}{l}\text { Calcium channel } \\
\text { blockers+ beta } \\
\text { blockers }\end{array}$ & $6.7 \%$ \\
\hline & $\begin{array}{l}\text { Calcium channel } \\
\text { blockers +ARB }\end{array}$ & $6.7 \%$ \\
\hline & $\begin{array}{l}\text { No antihypertensive } \\
\text { used }\end{array}$ & $6.7 \%$ \\
\hline & Others & $6.6 \%$ \\
\hline \multirow[t]{2}{*}{ Complications } & No complications & $93.3 \%$ \\
\hline & $\begin{array}{l}\text { Ischemic heart } \\
\text { disease }\end{array}$ & $6.7 \%$ \\
\hline Frequency of visits to & Weekly & $26.7 \%$ \\
\hline \multirow[t]{3}{*}{ healthcare facility } & Monthly & $40 \%$ \\
\hline & Once in 6 months & $13.3 \%$ \\
\hline & Others & $20 \%$ \\
\hline
\end{tabular}

\section{Discussion}

Our study showed the community prevalence rate of hypertension to be $9.6 \%$ which was similar to a study done in Tirupathi ${ }^{5}$ but lower compared to other studies ${ }^{(3,4)}$. This may be due to the fact that our sample size was low and our study was based on diagnosed hypertensives, also since BP recordings were not taken it may have led to underestimation of prevalence of hypertension.

Hypertension was observed in $5.9 \%$ of males and $12.5 \%$ of females contrary to other studies where prevalence was higher in males compared to females ${ }^{(4,5)}$. This may be due to the fact that ratio of female to male population is higher in our field practice area and also the proportion of older women is higher.

In our study $46.7 \%$ of people in age group $51-70$ years, $40 \%$ in the age group 31-50 years were hypertensives which was similar to another study ${ }^{5}$, whereas in the study conducted in Davangere higher prevalence of hypertensives were in the age group of over 70 years ${ }^{4}$

In our study we found that majority of hypertensives were on regular treatment which was similar to other studies ${ }^{(3,5)}$, but was better than the treatment pattern in a study conducted in Davangere where it was just 32.1\%.This may be due to the good literacy rate, awareness of health and presence of many medical college hospitals in the vicinity.

Majority of the hypertensives in our study use calcium channel blockers followed by beta blockers, ACE inhibitors and combination therapy was used least, when compared to a study conducted by Malhotra et all where majority of the patients used combination therapy followed by beta blockers, calcium channel blockers and ACE inhibitors ${ }^{6}$. Its good to know that this study population has been prescribed anti-hypertensives as per their indications which was the problem in earlier studies. Probably the health care access being not a problem in our setting has led to the evidence based treatment.

In our study household awareness about hypertension was low which was similar to other studies ${ }^{7.8}$ which may be due to the fact that although the population is aware about the disease, they are unaware of the causation, risk factors, role of lifestyle modification and complications associated with it, as many approach private clinics for their treatment where health education is not imparted appropriately.

\section{Conclusion}

In our study the prevalence of hypertension was found to be low and awareness regarding the same was poor. Treatment pattern showed that majority of the hypertensives were on regular treatment. It was noted that most of the hypertensives do not exercise, and there was no modification in the physical activity following diagnosis although diet modifications were seen in more than half of those diagnosed of hypertension. In our study we found that majority of the hypertensive population prefer private dispensaries over other healthcare facilities available.

\section{Limitations}

In our study only diagnosed hypertensives were included and BP recordings were not taken, as a result it may have led to underestimation of the prevalence of hypertension in the community.

\section{Recommendation}

Since the awareness about hypertension was found to be 
poor, there is a need for health education activities and awareness programme to be carried out in the community. These activities should emphasize on risk factors, physical activity and diet modifications.

\section{Implications}

This pilot study would add on to form a population based

\section{References}

1. WHO.2013. A global brief on hypertension. Geneva. WHO. [Internet]. [cited 2014 Sept 6]. Available from www.who.int/cardiovascular diseases/publications/global brief hypertension/en/

2. Épidemiology of Hypertension.JAPI suppl.february 2013;61:12-13.

3. Prevalence, awareness, treatment and control of hypertension among the elderly in Bangladesh and India: a multicentre study. Bulletin of the World Health Organization, 2001;79(6):491-500.

4. Yuvaraj BY, Nagendra Gowda MR, Umakantha AG. Prevalence, Awareness, Treatment, and Control of Hypertension in Rural Areas of Davanagere.IJCM .January2010;35(1):138-141.

5. S.S. Reddy, G. R. Prabhu.Prevalence and Risk Factors of Hypertension in Adults in an Urban Slum,Tirupati, A.P. IJCM. July-September 2005;30(3):84-86.

6. Samir Malhotra,R. Karan,P. Pandhi, Sanjay Jain.Pattern of use and pharmacoeconomic impact of antihypertensive drugs in a north Indian referral hospital.Eur J clin Pharmacol.2001;57:535-540.

7. Hemant Mahajan, Yasmeen Kazi, Bhuwan Sharma,GD Velhal. Assessment of KAP, Risk Factors and Associated Co-Morbidities in Hypertensive Patients.IOSRJ DM S. Sep-Oct. 2012;1(2):06-14

8. Yadlapalli S Kusuma. Perceptions on hypertension among migrants in Delhi, India: a qualitative study. BM CPublic Health. 2009;9:267. registry for cardiovascular diseases.

\section{Acknowledgements}

We would like to acknowledge II year M BBS students and Medicosocial workers $\mathrm{Mr}$ Santhosh, $\mathrm{Mr}$ Ravi and $\mathrm{Mr}$ Harsharaj for extending their help in data collection. 